\title{
Challenges in Urban Metabolism: Sustainability and Well-Being in Cities
}

\author{
Sergio Ulgiati ${ }^{1,2 *}$ and Amalia Zucaro ${ }^{3 *}$ \\ ${ }^{1}$ Department of Sciences and Technologies, Parthenope University of Naples, Naples, Italy, ${ }^{2}$ School of Environment, Beijing \\ Normal University, Beijing, China, ${ }^{3}$ Laboratory Resources Valorization, ENEA, Research Centre of Portici, Naples, Italy
}

Keywords: urban ecosystem, energy, resources - gains and losses, urban metabolism, food supply and demand, life cycle analysis

The concept of urban metabolism dates back to the nineteenth century (Wolman, 1965; Odum, 1996), since cities have become the engine of economic development and human well-being. The term urban metabolism, as emphasized by Céspedes Restrepo and Morales-Pinzón (2018) “is a concept in which the city is using the biological notion referring to the internal processes by which living organisms maintain a continuous exchange of matter and energy with their environment to enable operation, growth, and reproduction." Cities are complex ecosystems fully natural, even if we sometimes think human-made structures are not nature. Understanding cities is much easier if we are aware that they are natural ecosystems, obeying to the same laws (Lotka's maximum power principle, Darwin's evolution, natural selection) as all other compartments and species. Although cities cover $<2 \%$ of the earth's surface, they consume about $78 \%$ of the energy available on the planet, to which one must add the amount of materials and products (food, construction minerals, metals, etc.) that indirectly also require energy consumption. This figure can be explained in economic and social terms, as cities offer residents new opportunities for business, education, health services, security, social life. Supporting these activities (and related benefits) requires huge flows of resources, that most often translate into an environmental stress both locally and globally. Therefore, assessing the resource metabolism of an urban system, although very difficult due to its complexity, becomes increasingly crucial, not only concerning the relation with the environment as a source or a sink, but also concerning the internal dynamics of resource exchange among city components and sectors as well as competition among cities for scarce resources. Over the last few years, there has been an increasing interest in cities and their energy and material use-driven in part by climate change concerns and in part by social problems determined by the social and organization problems generated by the huge migration flows from rural to urban areas. Cities have a central role to play in the reduction of $\mathrm{CO}_{2}$ emissions and the fight against climate change, among the most serious challenges our society is presently facing (Zhang et al., 2018). Climate change is not the only problem determined by and affecting cities: the abandonment of rural areas, the demand for water to be diverted from natural pathways, the concentration of urban waste and the need for appropriate ways to dispose of them, the demand for transportation and the related space, energy and air pollution constraints, the huge amount of resources in support to urban lifestyles (education, health services, supply chain of food and manufactured goods, etc.), not only require energy and generate pollution, but are the potential source of new market dynamics, labor reorganization, conflicts, new governance tools and roadmaps, demand for community services and finally decline of previous cultural and social models and their replacement by new ones (or by nothing, even worse). Monitoring resource inflows and outflows and understanding how they relate to population, resource availability, and environmental carrying capacity is crucial for aware and concerned urban sustainability policies and governance. Reorganizing cities' structures linking 
biophysical aspects with social, well-being community aspects, is a priority challenge in policy making worldwide. To influence urban metabolism, we need to have a better understanding of the relations between societies, environment, mass and energy flows (production and consumption) without underestimating the population growth factor. Well-being, not wealth or affluence, is going to be the keyword for the future of cities, namely an aware and balanced relation of a city population with surrounding environment, resources, other species, in order to promote fair and equitable access to social, cultural, economic, health improvements not necessarily linked to increased per-capita resource consumption.

The distribution of human population worldwide clearly shows that more and more people have been moving from countryside to cities, leading to increased problems of (and awareness about) energy and resource availability and use, urban development, and environmental integrity (Cui, 2018). According to United Nations reports, 43 megacities (i.e., cities with more than 10 million inhabitants) will exist by 2030, most of which in developing countries (United Nations, 2018b). The largest fraction of world population expected to live in cities or megacities and the expected significant modification of living styles, supply chains, governance patterns, community organization, waste production, education tools and structures, and more in general environmental, economic and social dynamics, translate into the urgent need for comprehensive studies on urban sustainability and well-being.

Urban systems and cities are complex entities with their own metabolism, extremely dependent for various material and energy inputs from outside their boundaries (Currie et al., 2017). The water-energy nexus in urban system, considering the consumption patterns of water and energy in buildings, residential sectors and production sectors, can provide important insights for sustainable city planning (Fan et al., 2019). Resource metabolism affects and is affected by the way urban communities self-organize and make decisions, consume and save, degrade and recycle resources, share community services, design, and use infrastructures. Nevertheless, the community aspect and management of resource metabolism are still poorly explored. A second important topic is the way urban systems relate to the surrounding rural areas and wilderness, respect them, help them develop and keep their integrity patterns (Wei et al., 2015). Finally, much has been written about de-growth of assets, population and consumption, but this was very much limited to quantitative de-growth, without exploring still possible patterns of qualitative growth, in terms of job quality, safety, community interaction, sharing, happiness, fair access to resources at all levels and participatory processes. This is likely the most difficult but also the most crucial aspect of sustainability and stability of cities. An urban integrative governance, through appropriate management and environmental assessment of the benefits and trade-offs with regard to development planning, infrastructure spatial planning as well as corresponding auxiliary intervention, becomes fundamental (Fan et al., 2019). Instead of merely addressing urban development and eco-environmental preservation, city planners should always be conscious of sustainability aspects related to the quality and typology of metabolism (Cui, 2018). The problem is not to maximize or ensure huge energy supply or the largest possible amount and variety of food or the fastest possible transport, but instead to optimize at all levels the access of the entire urban population to services, goods, education, leisure, health services, environmental quality to a sufficient extent to ensure quality of life, stability, fairness, and respect.

The well-being in cites, also called city livability, represents the city's ability to provide adequate conditions for citizens to thrive and have a good quality of life (del Mar MartínezBravo et al., 2019). The resources availability and their fair distribution/allocation, the individual perceptions, the different community organization and conditions (e.g., educational levels, public services, free time availability, green area willingness, among others), the environmental awareness, the social and economic development are interlinked issues that highly influence a city metabolism. The sustainability and well-being of urban areas has been a topic of discussion both in the scientific world (Wei et al., 2015; del Mar Martínez-Bravo et al., 2019) as well as policy debates (United Nations, 2018a) due to the crucial link among growth, natural resources exploitation (use of nonrenewable energy and materials) and consequences on the state of the environment.

Urban systems have been widely investigated by means of several different economic and biophysical approaches. Performance indicators for cities, regions and nations have been developed, based on well-known assessment methods, sometimes integrated into a specific toolkit: embodied energy, material flow analysis (MFA), life-cycle analysis (LCA), $\mathrm{CO}_{2}$ emissions, cost/benefit and economic returns (Yong et al., 2012). These indicators individually or in combination do not necessarily provide a fully adequate characterization of an urban system environmental integrity and resource use, since they were not designed to assess whole-systems, closedloops, and feedback features that are key characteristics of a sustainable urban economy (Yong et al., 2013). Most often these approaches disregard flow quality and characteristics as well as the complexity of interactions between the natural environment and socioeconomic systems (Huang et al., 2006). Therefore, it is fundamental to discuss and to deeper understand the complexity of future city development and management, going much beyond the linear and mono-dimensional approach of just measuring a city population or energy consumption or GDP. Linking urban metabolism to policy strategies it is necessary in order to measure and change urban sustainability performances, developing interdisciplinary practice of urban metabolism (Dijst et al., 2018). Social behavior and individual preferences are deeply affected by competition for available resources, space, opportunities. It is impossible to have an educated next generation without investing into education; impossible to enjoy healthy food without investing resources in cleaner production; impossible to have a stable and happy community without ensuring equitable access to basic resources. As a consequence, appropriate and fair resource management is likely to affect (and be affected by) education, democracy, stability, sense of belonging, balanced interaction with surrounding areas and populations. 
One of the most demanding challenges for the near future is to develop new environmental strategies and alternatives to fossil energy, with the aim to address the needs and expectations of the present and future generations in a sustainable way. In times of shrinking resource basis more circular and flexible resource supply patterns coupled to life style changes might be the basis for less resource intensive urban life (Zucaro et al., 2014). Since an urban area is a complex system related to different production/consumption supply chains, the investigation of environmental, economic and social aspects with a systemwide analysis framework toward sustainability is a key issue to safeguard the well-being and develop adequate political choices. Even if energy efficiency and renewable energy implementation as well as material recycling patterns (circular economy) seem to be developing quickly and effectively, there is still much to be done. Society is a complex network of production and consumption activities, linked to each other over interacting supply and trade chains. Not necessarily the energy efficiency improvement in one point of the network (e.g., due to recycling or resource exchange or circular economy patterns implementation) translates into an overall efficiency improvement at the level of the entire system; in a like manner, the abatement of one kind of impact (energy depletion, water depletion, land demand, emissions, etc.) does not necessarily translate into an overall abatement of system's impacts. Therefore, the research on urban metabolism should urgently get engaged on designing sustainability solutions for socio-ecological dynamics describing and understanding the

\section{REFERENCES}

Céspedes Restrepo, J. D., and Morales-Pinzón, T. (2018). Urban metabolism and sustainability: precedents, genesis and research perspectives. Resour. Conserv. Recycl. 131, 216-224. doi: 10.1016/j.resconrec.2017. 12.023

Cui, X. (2018). How can cities support sustainability: a bibliometric analysis of urban metabolism. Ecol. Indic. 93, 704-717. doi: 10.1016/j.ecolind.2018. 05.056

Currie, P. K., Musango, J. K., and May, N. D. (2017). Urban metabolism: a review with reference to Cape Town. Cities 70, 91-110. doi: 10.1016/j.cities.2017.06.005

del Mar Martínez-Bravo, M., Martínez-del-Río, J., and Antolín-López, R. (2019). Trade-offs among urban sustainability, pollution and livability in european cities. J. Clean. Prod. 224, 651-660. doi: 10.1016/j.jclepro.2019.03.110

Dijst, M., Worrell, E., Böcker, L., Brunner, P., Davoudi, S., Geertman, S., et al. (2018). Exploring urban metabolism-Towards an interdisciplinary perspective. Resour. Conserv. Recycl. 132, 190-203. doi: 10.1016/ j.resconrec.2017.09.014

Fan, J. L., Kong, L. S., Wang, H., and Zhang, X. (2019). A water-energy nexus review from the perspective of urban metabolism. Ecol. Modell. 392, 128-136. doi: 10.1016/j.ecolmodel.2018.11.019

Huang, S. L., Lee, C. L., and Chen, C. W. (2006). Socioeconomic metabolism in Taiwan: emergy synthesis versus material flow analysis. Resour. Conserv. Recycl. 48, 166-196. doi: 10.1016/j.resconrec.2006.01.005

John, B., Luederitz, C., Lang, D. J., and von Wehrden, H. (2019). Toward sustainable urban metabolisms. from system understanding to system transformation. Ecol. Econ. 157, 402-414. doi: 10.1016/j.ecolecon.2018. 12.007

Odum, H. T. (1996). Environmental Accounting: Emergy and Environmental Decision Making. New York, NY: Wiley-Indersciene. interdependencies and dynamics of cities and the ecosystems (John et al., 2019).

Discussion, dialogue, participatory governance, and appropriate problem-solving processes based on a suitable quantitative and qualitative information are essential aspects in order to design an appropriate decision-making development for urban metabolism patterns that are restorative from both intention and design, in order to achieve the sustainability and well-being goals.

Sustainability is something that will occur in cities, or is unlikely to happen. Moving from sustainability rhetoric to community and well-being implementation is something that will not come by itself, nor can be addressed by means of linear and deterministic approaches. Similar to ecosystems, cities require optimization of resource use in all sectors and levels, interlinkages among components and processes, urban-rural balanced collaboration, patterns for recovery and recycling of residues and waste, pulsing strategies according to oscillating resource availability, education programs oriented to deeper understanding of complexity environmental constraints, strategies toward qualitative growth instead of pursuing unlimited and hardly sustainable quantitative growth.

\section{AUTHOR CONTRIBUTIONS}

All authors listed have made a substantial, direct and intellectual contribution to the work, and approved it for publication.

United Nations (2018a). United Nations Environment Programme, The Weight of Cities. Available online at: https://www.unenvironment.org/news-and-stories/ story/weight-cities.

United Nations (2018b). World Urbanization Prospects: The 2018 Revision.

Wei, H., Shenghui, C., Yarime, M., Hashimoto, S., and Managi, S. (2015). Improving urban metabolism study for sustainable urban transformation. Environ. Technol. Innov. 4, 62-72. doi: 10.1016/j.eti.2015.04.004

Wolman, A. (1965). The metabolism of cities. Sci. Am. 213, 178-190.

Yong, G., Fu, J., Sarkis, J., and Xue, B. (2012). Towards a national circular economy indicator system in China: an evaluation and critical analysis. J. Clean. Prod. 23, 216. doi: $10.1016 /$ j.jclepro.2011.07.005

Yong, G., Sarkis, J., Ulgiati, S., and Zhang, P. (2013). Measuring China's circular economy. Science 339, 1526-1527. doi: 10.1126/science.1227059

Zhang, Y., Wua, Q., and Fath, B. D. (2018). Review of spatial analysis of urban carbon metabolism Ecol. Modell. 371, 18-24. doi: 10.1016/j.ecolmodel.2018.01.005

Zucaro, A., Ripa, M., Mellino, S., Ascione, M., and Ulgiati, S. (2014). Urban resource use and environmental performance indicators. An application of decomposition analysis. Ecol. Indic. 47, 16-25. doi: 10.1016/j.ecolind.2014.04.022

Conflict of Interest Statement: The authors declare that the research was conducted in the absence of any commercial or financial relationships that could be construed as a potential conflict of interest.

Copyright (๑) 2019 Ulgiati and Zucaro. This is an open-access article distributed under the terms of the Creative Commons Attribution License (CC BY). The use, distribution or reproduction in other forums is permitted, provided the original author(s) and the copyright owner(s) are credited and that the original publication in this journal is cited, in accordance with accepted academic practice. No use, distribution or reproduction is permitted which does not comply with these terms. 